\title{
RADIO PUBLICZNE W INDYWIDUALNYCH REPERTUARACH MEDIÓW ${ }^{1}$
}

\author{
Abstract

\section{PUBLIC RADIO IN INDIVIDUAL MEDIA REPERTOIRES}

At present, when there are so many news media platforms, the use of media consists in building personal, specific repertoire. These repertoires are a combination of many factors, including the available reception platforms, the geographical and social coverage of the media, the interests and needs of users. In this article I try to answer the question of how, in a very competitive media market, media users, by building their own individual media repertoires as a source of the news needed in everyday life and treated as a resource of democracy, use public radio. Through qualitative in-depth interviews with audiences of different social and demographic profiles in 8 European countries and Israel, the perception of the role of the news and current affaire of public radio organisations and understanding of their remit was examined.

Key words: radio, public service media news, media repertoires, factor analysis, media audience

\section{Wprowadzenie}

Koncepcja radiofonii i telewizji publicznej, jej raison d'être oraz sposoby finansowania ich działalności wciąż są przedmiotem żywej debaty. Wraz z nowym środowiskiem technologicznym i prawnym, różnorodnością oferty mediów, z rozwojem

1 Artykuł jest zmodyfikowaną i uzupełnioną wersją artykułu Public Service Media News Consumption across Europe: Views from a Q-Methodological Repertoire Study, „Participation. Journal of Audience \& Reception Studies" 2017, t. 14, nr 2. 
wielonarodowych mediów i branży IT sytuacja ulega zmianie. Rosnąca w wielu krajach rola prywatnych nadawców, krajobraz mediów nasycony mediami cyfrowymi, mobilnymi i społecznościowymi osłabiły dotychczas dominującą pozycję organizacji mediów publicznych (Public Service Media) i rozdrobniły widownię. Tymczasem nadawcy publiczni są nadal zobowiązani do służenia całemu społeczeństwu poprzez wzmacnianie obywatelstwa społecznego, politycznego i kulturalnego ${ }^{2}$. W tym celu udostępniają treści multimedialne, które cechuje ${ }^{3}$ :

- otwarty do nich dostęp,

- wysoka jakość,

- dokładność i odpowiedzialność za słowo.

Chociaż stopień rozdrobnienia rynku różni się znacznie w zależności od kraju, ogólna tendencja pozostaje od lat mniej więcej taka sama: więcej operatorów i więcej kanałów programowych oferuje odbiorcom nowe opcje radiowe i telewizyjne, czego wynikiem jest długotrwały spadek liczby i znaczenia kanałów publicznych ${ }^{4}$. Organizacje publiczne mediów w Europie reagują w różny sposób na coraz bardziej mobilne i interaktywne środowisko mediów, w którym tradycyjne kanały telewizyjne i radiowe są relatywnie mniej ważne niż w przeszłości.

Badania przeprowadzone $\mathrm{w}$ wielu krajach podkreślają potrzebę opracowania nowego modelu PSM i stworzenia nowego dyskursu i narracji wobec mediów publicznych oraz nowych sposobów udziału społeczeństwa w rozwoju PSM jako zrewitalizowanego tła obywatelstwa ${ }^{5}$. W tym artykule, biorąc pod uwagę dane ilościowe i jakościowe pochodzące $\mathrm{z}$ badań nad korzystaniem z różnych mediów, analizuję, w jaki sposób ludzie na bardzo silnie konkurencyjnych rynkach medialnych w Europie wykorzystują radio publiczne jako źródła informacji w swoich indywidualnych repertuarach mediów. W ten sposób badania te stanowią uzupełnienie obrazu, jaki wynika z badań rynkowych.

\section{Metodologia}

Przedstawione poniżej dane pochodzą z międzynarodowych badań zrealizowanych w latach 2014-2015 w ośmiu krajach europejskich i w Izraelu. Wykorzystano w nich metodę Q-sorting, która umożliwia konstruowanie wzorców korzystania $\mathrm{z}$ mediów i odtworzenie doświadczeń związanych z konsumpcją mediów. Metoda

2 Protokół amsterdamski do Traktatu Europejskiego, Bruksela 1997.

${ }^{3}$ D. McQuail, Teoria masowego komunikowania, Wydawnictwo Naukowe PWN, Kraków 2007.

${ }^{4}$ R. Fletcher, R.K. Nielsen, Are News Audiences Increasingly Fragmented: A Cross-National Comparative Analysis of Cross-Platform News Audience Fragmentation and Duplication, „Journal of Communication" 2017, t. 67, nr 4.

${ }^{5}$ M.A. Horowitz, Public Service Media and Challenge of Crossing Borders: Assessing New Models, „Medijskie Studije” 2015, t. 6, nr 12, s. 80-91. 
ta syntetyzuje podejścia jakościowe i ilościowe ${ }^{6}$. Jej zaletą jest to, że umożliwia analizę czynnikową z wykorzystaniem danych pochodzących od stosunkowo niewielkiej liczby badanych. W badaniach dotyczących krzyżowego wykorzystania wiadomości wzięło udział 36 osób w każdym z uczestniczących krajów różniących się pod względem kluczowych cech demograficznych i społecznych. Próba składała się z osób obu płci, trzech grup wiekowych (18-34 lata, 35-60 lat, 61+), trzech poziomów edukacji (poziomu średniego, BA - licencjat i MA - wykształcenie wyższe) oraz trzech typów miejscowości (stolica, duże miasto i małe miasto prowincjonalne). W Polsce badania zostały zrealizowane w marcu i kwietniu 2015 roku w Warszawie, Toruniu i Otwocku.

W głównej części badania, w toku pogłębionych wywiadów, badani zostali poproszeni o posortowanie 36 ponumerowanych kart reprezentujących platformy lub formaty mediów informacyjnych i uzasadnienie swoich wyborów. Sortowanie polegało na wskazaniu kart (mediów) zgodnie z rolą, jaką odgrywają poszczególne media informacyjne w życiu codziennym danej osoby, poprzez umieszczenie ich $\mathrm{w}$ siatce przypominającej piramidę. Badani zostali poproszeni o umieszczenie kart (mediów), które nie odgrywają roli w ich codziennym życiu, po lewej stronie, zaś po prawej stronie miały znaleźć się te, które odgrywają znaczącą rolę w ich codziennym życiu. Mediom w skrajnie lewym końcu siatki (najmniej ważne) została przypisana wartość -4 , a skrajnie prawy koniec siatki (najważniejsze media) otrzymał wartość +4 . Kontinuum pomiędzy tymi skrajnościami otrzymywało wartości od minus do plus 4, dzięki czemu badany przypisywał wartość każdej karcie zawierającej nazwę konkretnego medium lub konkretnego gatunku programowego. Otrzymane wyniki były podstawą analizy czynnikowej, która tworzyła charakterystyczny zestaw repertuarów mediów w każdym z uczestniczących w badaniach krajów.

\section{Pozycja radia publicznego $w$ krajach uczestniczących w badaniach i ekspozycja ich oferty informacyjnej}

Badania nad korzystaniem $\mathrm{z}$ mediów i kształtem oraz mechanizmami budowy własnych indywidualnych repertuarów w warunkach przenikających się platform medialnych, które zrealizował międzynarodowy zespół badawczy, zmierzają w istocie do tego, by rozpoznać wzory korzystania $z$ mediów i doświadczenia związane $\mathrm{z}$ konsumpcją wiadomości przekazywanych przez media, $\mathrm{w}$ tym radio publiczne $\mathrm{e}^{7}$. Jednym z najważniejszych warunków wstępnych korzystania $\mathrm{z}$ oferty informacyjnej i publicystycznej mediów publicznych, a także podstawy kształtowania postaw

${ }^{6}$ K.Ch. Schrøder, Methodological Pluralism as a Vehicle of Qualitative Generalization, „Participations: Journal of Audience and Reception Studies” 2012, t. 9, nr 2, s. 798-825.

7 H. Adoni, H. Nossek, K.Ch. Schrøder, Cross-Media News Repertoires as Democratic Resources: A Cross-Cultural Research Project, 2013 (w przygotowaniu). 
wobec nich jest ekspozycja tej oferty w środowisku medialnym, którą wyznacza pozycja danej organizacji publicznej na rynku mediów i poziom jej wiarygodności. Przesądza to o większej skłonności odbiorców do korzystania z oferty programowej organizacji publicznych, w tym audycji informacyjnych i publicystycznych, które w największej mierze zaspokajają potrzebę orientacji w otaczającym świecie i składają się na informacyjny potencjał demokracji.

Raporty EBU (Europejska Unia Nadawców Publicznych) opracowywane na podstawie badań rynkowych w poszczególnych krajach wskazują na zróżnicowany udział radia publicznego w rynku w krajach uczestniczących w badaniach8

Największy dzienny udział radia publicznego w rynku o zasięgu ogólnokrajowym charakteryzuje Danię - 74,3\%, Belgię (nadawca flamandzki) - 62,1\%, Niemcy - 55,7\%, mniejszy Belgię (nadawca waloński) - 36,2\%, Estonię - 34,1\%, Holandię 30,6\%, jeszcze mniejszy Polskę - 18,3\% i Chorwację - 18,9\%, a najmniejszy Portugalię - 9,5\% i Hiszpanię - 7,1\%.

Istotnym wskaźnikiem potencjału informacyjnego radiowych nadawców publicznych jest liczba stacji radiowych w krajach uczestniczących w badaniach (zob. tabela 1). Najwięcej publicznych stacji radiowych działa w Niemczech, Polsce, Holandii i Hiszpanii. Najmniej - w Estonii, Belgii, Portugalii i Izraelu. Oczywiście w największym stopniu ma to związek z wielkością terytorium danego kraju, ale też z charakterem systemu politycznego i systemu medialnego (np. Niemcy - system federalistyczny, Belgia - federacja dwóch wspólnot językowych).

Tabela 1. Liczba publicznych stacji radiowych w poszczególnych krajach w 2015 roku

\begin{tabular}{|l|l|l|}
\hline \multicolumn{1}{|c|}{ Kraj } & \multicolumn{1}{c|}{ Radio (ogólnokrajowe) } & \multicolumn{1}{c|}{ Radio (regionalne) } \\
\hline Belgia flamandzka & 9 & 5 \\
\hline Belgia francuska & 5 & n/a \\
\hline Chorwacja & 11 & 8 \\
\hline Dania & 11 & 11 \\
\hline Niemcy & 63 & 66 \\
\hline Izrael & 7 & n/a \\
\hline Holandia & 6 & n/a \\
\hline Polska & 4 & 17 \\
\hline Portugalia & 3 & 3 \\
\hline
\end{tabular}

Źródło: opracowanie własne na podstawie Radio Audience Trends, MIS EBU, Geneva 2015.

Innym ważnym wskaźnikiem potencjału medialnego i informacyjnego poszczególnych krajów uczestniczących w badaniach jest łączny czas antenowy

${ }^{8}$ Audience Trends: Media Consumptions, MIS EBU, Geneva 2015. 
audycji i programów informacyjnych w publicznym radiu jako rezerwuar, z którego mogą korzystać odbiorcy i użytkownicy mediów (zob. tabela 2). Tutaj w sektorze radiowym przoduje Dania.

Tabela 2. Radio publiczne: potencjał informacyjny

\begin{tabular}{|l|l|l|}
\hline \multicolumn{1}{|c|}{ Kraj } & \multicolumn{1}{|c|}{ Radiowa organizacja publiczna } & \multicolumn{1}{|c|}{$\begin{array}{c}\text { liczba godzin } \\
\text { dziennie }\end{array}$} \\
\hline Chorwacja & HRT & 94 \\
\hline Dania & DR & 39 \\
\hline Polska & PR & 18 \\
\hline Belgia walońska & RTBF & 16 \\
\hline Belgia flamandzka & VRT & 8 \\
\hline Portugalia & RTP & 5 \\
\hline Holandia & NPO & n/a \\
\hline Niemcy & ARD & n/a \\
\hline
\end{tabular}

Źródło: opracowanie własne na podstawie Media Eurobarometer, MIS EBU, Geneva 2015 (nie uwzględnia Izraela).

Zarówno liczba programów informacyjnych i publicystycznych, jak i czas ich emisji jest $\mathrm{z}$ jednej strony miarą ich ekspozycji w przestrzeni komunikacyjnej poszczególnych krajów, a z drugiej - obiektywną miarą pozycji zajmowanej w tych krajach przez radiowych nadawców publicznych i wyznacznikiem ich potencjału informacyjnego.

Jeszcze jednym wskaźnikiem potencjału radiofonii publicznych w poszczególnych krajach jest poziom zaufania do tych nadawców i treści, jakie oferują ${ }^{9}$. W 2015 roku, to znaczy w czasie, gdy realizowano badania, w Europie najbardziej godnym zaufania medium - w porównaniu z prasą, telewizją, Internetem i portalami społecznościowymi - było radio. Najwyższy poziom zaufania do radia charakteryzował kraje nordyckie - Szwecję, Finlandię i Danię. Poziom zaufania do radiowych organizacji publicznych był dość zróżnicowany, gdy spojrzeć na ewolucję tej wartości w latach 2011-2015. Publiczne radiofonie w krajach skandynawskich, w mniejszym stopniu w Polsce i Portugalii, a najmniejszym w Chorwacji cieszyły się wzrastającym poziomem zaufania, podczas gdy w Belgii, Holandii i Niemczech tendencja była odwrotna. Trzy wskazane wymiary pozycji radiofonii publicznych pokazują potencjalny wpływ publicznych nadawców radiowych na opinię publiczną.

9 Trust in Media, EBU, Media Intelligence Service 2016, na podstawie Eurobarometer 84. 


\section{Obecność radiowych nadawców publicznych w indywidualnych repertuarach mediów}

W badaniach spróbowano określić poziom obecności radiowych stacji publicznych $\mathrm{w}$ repertuarach mediów zbudowanych przez badanych w poszczególnych krajach, a także wskazać czynniki, jakie skłaniają odbiorców do korzystania z oferty nadawców publicznych. Jak już wspomniałem, założono, że im wyższa pozycja radiowych nadawców publicznych na rynku i silniejsza ekspozycja ich oferty programowej, $\mathrm{w}$ tym zwłaszcza informacji i publicystyki w przestrzeni komunikacyjnej danego kraju, tym większa skłonność odbiorców do korzystania z ich oferty programowej. Postawę tę i zachowania odbiorcze obrazuje wartość średniej w przedziale rozciągającym się od -4 do 4 , zatem od mediów, które odgrywają najmniejszą rolę w życiu codziennym użytkowników, do tych, które odgrywają rolę największą. W zestawie mediów, jakie mieli do dyspozycji badani, znalazły się trzy kategorie radia publicznego: serwisy informacyjne radia publicznego i serwisy online oferowane przez radiowych nadawców publicznych, czyli kategorie nr 9 i 24 (zob. załącznik).

Jak wynika z tabeli 3, najwyższe wartości osiągają średnie dla Belgii (Flandria), Niemiec, Danii, niższe dla Belgii walońskiej i Holandii, jeszcze niższe dla Chorwacji i Polski, a najniższe dla Izraela i Portugalii. Niewątpliwie wartości średnich wskazują na pozycję nadawców publicznych w wymienionych krajach postrzeganą przez odbiorców korzystających z ich oferty.

Tabela 3. Średnie dla mediów publicznych (telewizja, radio, portale internetowe) w próbach $\mathrm{z}$ badanych krajów ${ }^{10}$

\begin{tabular}{|l|l|}
\hline \multicolumn{1}{|c|}{ Kraje } & Media publiczne (telewizja, radio, portale internetowe) \\
\hline Belgia walońska & 2,4907 \\
\hline Belgia francuska & 1,5370 \\
\hline Chorwacja & 0,9815 \\
\hline Dania & 1,7593 \\
\hline Izrael & 0,5370 \\
\hline Holandia & 1,4630 \\
\hline Polska & 1,0370 \\
\hline Portugalia & 0,5093 \\
\hline Niemcy & 1,7407 \\
\hline Ogólnie & 1,3395 \\
\hline
\end{tabular}

10 Średnia dla trzech mediów łącznie: radio, telewizja i portal internetowy organizacji publicznych. 


\section{Radio publiczne w repertuarach mediów informacyjnych - dane jakościowe}

Wypowiedzi przytaczane $\mathrm{w}$ tej części artykułu pochodzą z pogłębionych wywiadów, które zostały przeprowadzone w uczestniczących w badaniach krajach wśród 36 osób dobranych według wspólnych kryteriów demograficznych i społecznych. W ramach tych wywiadów, w wyniku których powstawały indywidualne repertuary mediów, badani $\mathrm{w}$ istocie tworzyli własny świat mediów informacyjnych. W tym świecie, jak się okazało, ważną rolę odgrywają media publiczne. Wypowiedzi osób badanych - o tym, dlaczego są dla nich ważne, kiedy i w jaki sposób je odbierają, jakich treści w nich poszukują itd. - są zarazem uzasadnieniem, jak i rozszerzeniem wyborów dokonywanych przy budowie indywidualnych repertuarów mediów.

Większość fragmentów wypowiedzi badanych prezentowanych w tej części artykułu pochodzi z polskiej części projektu, niemniej są one uzupełnione przykładami z Danii, Izraela, Niemiec, Holandii i Belgii flamandzkiej. Badacze, którzy przeprowadzili te badania w swoich krajach, potwierdzili, że dyskurs na temat postrzegania mediów publicznych, przedstawiony poniżej, jest dość typowy dla krajów uczestniczących. Niemiecki repertuar (R1: Public Service Broadcasting) i polski repertuar (R4: PSM Followers) są poświęcone użytkownikom gatunków informacyjnych nadawców publicznych, a przykłady holenderskie, flamandzkie, duńskie i izraelskie pochodzą z różnych repertuarów, na przykład repertuar (R1: Conservative Mainstream: Old Media) w badaniach izraelskich oraz repertuar flamandzko-belgijski o kosmopolitycznym poszukiwaniu jakości.

Polska część opracowania zawierała pięć repertuarów.

\begin{tabular}{|l|l|}
\hline Repertuar 1: & $\begin{array}{l}\text { użytkownicy głównych komercyjnych kanałów telewizyjnych i radiowych } \\
\text { (12 badanych); }\end{array}$ \\
\hline Repertuar 2: & wszystkożerni użytkownicy mediów (10 badanych); \\
\hline Repertuar 3: & fani nowych mediów (5 badanych); \\
\hline Repertuar 4: & zwolennicy mediów publicznych (6 badanych); \\
\hline Repertuar 5: & czytelnicy prasy opiniotwórczej (3 badanych). \\
\hline
\end{tabular}

Wyboru repertuaru $4 \mathrm{w}$ części polskiej badań dokonały w większości osoby związane ze stolicą, korzystające $\mathrm{z}$ oferty nadawców publicznych, Polskiego Radia i Telewizji Polskiej. Osoby takie preferują jako źródło informacji media tradycyjne, zwłaszcza radio.

Radio jest niezastąpione. Mogę słuchać cały dzień (...). Nie interesuję się portalami internetowymi (...). Dyskutuję z mężem (...). Chcę poznawać ludzi i ludzką kulturę. Uważam, że jesteśmy manipulowani przez media. One nie integrują ludzi. Boję się o przyszłość młodych ludzi (\#7, Warszawa, kobieta, 61+, licencjat). 
Radio przez cały czas (Trójka). To jest to, jak zdobywać informacje. Słuchamy bardzo dużo podczas obiadu, wieczorem, wcześnie rano, po wstaniu z łóżka (\#29, Toruń, kobieta, 18-34 lata, wykształcenie wyższe).

Badany w repertuarze 2 (hybrydowi miłośnicy mediów publicznych) z części duńskiej badań konkluduje w taki sposób:

Rano i po południu, kiedy prowadzę samochód, słuchamy radia DR PR1 (program dla ludzi wykształconych). Lubię taki sposób prowadzenia programu, gdzie są dyskusje na różne tematy, wyjaśnienia, zamiast headlinów i konfliktów (\#2, miasto prowincjonalne, kobieta, 54 lata, wykształcenie wyższe).

Badany \#3 (miasto prowincjonalne, mężczyzna, 35-60, wykształcenie średnie) z repertuaru 2 (Quality - seeking cosmopolitan) Belgii flamandzkiej uznaje media publiczne za bardziej wartościowe, gdy chodzi o przekazywane informacji, ponieważ „są bliżej wydarzeń i reagują szybciej”. Publiczne media przekazują newsy „bardziej wiarygodne”. Badana \#5 z belgijskiej Flandrii (miasto prowincjonalne, kobieta, 35-60, licencjat) dodaje, że serwisy radiowe są „krótkie, niezbyt rozwlekłe i podawane co godzinę, a przez to łatwiejsze do zapamiętania”.

Badani podkreślają też tę szczególną właściwość, jaką jest newsworthiness - jakość serwisów informacyjnych ze względu na aktualną treść i interesującą formę prezentacji. Jeszcze inni zwracają uwagę na to, że oferta mediów publicznych podlega selekcji w zależności od indywidualnych, specyficznych zainteresowań. Mogą to być zainteresowania bieżącymi wydarzeniami, które obrazują główne wydania telewizyjnych magazynów informacyjnych, ale też zainteresowania zogniskowane na ważnych dla ludzi kwestiach dotyczących ich sytuacji życiowej, poczucia dyskryminacji, subiektywnych krzywd wyrządzanych na skutek błędnych decyzji władz publicznych i administracyjnych, niesprawiedliwych wyroków sądów powszechnych itd., które podejmują nieznane gdzie indziej tzw. programy interwencyjne.

$\mathrm{W}$ wywiadach pogłębionych przeprowadzonych w związku z projektem badawczym, o którym mowa w artykule, badani wskazywali różne okoliczności słuchania radia i innych stacji pełniących funkcje informacyjne, np. TOK FM czy - na przeciwległym biegunie - Radio Maryja.

Słucham Radio Maryja, również wiadomości. Uważam, że to stacja najbardziej wiarygodna (\#21, Otwock, kobieta, 61+, wykształcenie średnie).

Słucham też radia TOK FM. Mogę posłuchać dyskusji osób związanych z ważnymi wydarzeniami” (\#6, Warszawa, mężczyzna, 18-34 lata, mgr).

Badani zwracali też uwagę na informacyjne funkcje stacji muzycznych, wymieniając stacje, których zwykle słuchają. Wśród nich:

RMF FM: „Słucham RMF FM, najlepsze newsy, zawsze aktualne” (\#12, mężczyzna, 18-34 lata, Warszawa, licencjat). 
Radio ZET: „Radia słucham cały czas. Włączam po przebudzeniu. To jest głównie Radio ZET, oni nadają serwisy informacyjne co 30 minut. Rzadziej TOK FM. Radio ZET ma lepszy serwis, podczas gdy RMF FM - lepszą muzykę".

Radio Gra: „Słucham radia, gdy prowadzę samochód. Radio Gra w Toruniu ma aktualne informacje o charakterze krajowym i lokalnym" (\#31, Toruń, kobieta, 18-34 lata, licencjat).

Antyradio, Radio Rock: „Słucham zarówno Antyradio, jak i Radio Rock. Tam jest głównie muzyka, a serwisy informacyjne - bardzo krótkie, zwykle jakieś sensacje i skandale" (\#4, Warszawa, mężczyzna, 35-60 lat, wykształcenie średnie).

Złote Przeboje: „Nieczęsto słucham radia. Jeżeli już, to głównie muzyki w takich stacjach jak np. Złote Przeboje” (\#23, Otwock, mężczyzna, ponad 20 lat, licencjat).

Tych stacji muzycznych słucha się zwykle, jadąc samochodem lub podczas pracy. Skupienie na treściach informacyjnych, a zapewne również publicystycznych odbywa się podczas weekendów:

Częściej słucham radia podczas weekendów, gdy mam więcej czasu, albo wtedy, gdy coś ważnego się dzieje (\# 14, kobieta, 18-34 lata, wykształcenie wyższe, Otwock).

Niektórzy, zapewne traktując radio jako „tapetę dźwiękową”, słuchają radia muzycznego podczas pracy.

\section{Konkluzje}

Pomimo wielu zjawisk świadczących o kryzysie mediów publicznych i poszukiwaniach nowego modelu (modeli) funkcjonowania nadawców publicznych, sektor publiczny mediów ciągle odgrywa ważną rolę w codziennym życiu wielu społeczeństw, zwłaszcza w Europie. Nadawcy publiczni są też istotnym źródłem informacji o otaczającym świecie i ważnym ogniwem politycznej debaty.

W narzędziu badawczym zastosowanym w badaniach nad konsumpcją wiadomości płynących z różnych, krzyżujących się platform nadawczych, wśród 36 mediów informacyjnych znalazły się tylko dwa związane z radiem publicznym:

- serwisy informacyjne w ogólnokrajowym lub regionalnym programie radia publicznego;

- serwisy informacyjne online publicznego nadawcy radiowego.

$\mathrm{Z}$ analizy danych ilościowych oraz jakościowych (ograniczonych do części polskiej badań) wynika, że korzystanie z wiadomości przekazywanych przez publiczne radio ma związek z pozycją i ekspozycją oferty programowej tego sektora mediów, przede wszystkim treści o charakterze informacyjnym i publicystycznych 
- objaśniających świat. Konsumpcja wiadomości przekazywanych przez publiczne stacje radiowe jest intensywniejsza w krajach o silnej pozycji nadawców publicznych (w przeprowadzonych badaniach - w Niemczech, w obu częściach Belgii, w Danii i Holandii).

Typologia praktyk korzystania z mediów - ustalona w skonstruowanych na podstawie analizy czynnikowej repertuarach mediów - nie jest reprezentatywna dla mieszkańców Polski i innych krajów, w których odbyły się badania. Jednak zgodnie z logiką metody analizy danych Q-sorting typologię tę i praktyki - biorąc pod uwagę wystarczającą różnorodność społeczną i demograficzną badanych można uznać za odzwierciedlające w przybliżeniu obraz rzeczywistości społecznej.

Z kolei analiza danych jakościowych ograniczona do próby polskiej ujawniła różnorodne okoliczności i motywy sięgania odbiorców - użytkowników mediów do treści informacyjnych przekazywanych w programach radiofonii publicznych. Ukazała też, jaką estymą cieszy się radio jako medium, zwłaszcza niektóre programy radia publicznego (Trójka). Radio jest traktowane jako „towarzysz codzienności", tło rutynowych zajęć, ale równocześnie ważne źródło informacji i narracji o świecie.

Niezależnie od tego, czy praktyka odbiorcza dotyczy radia czy telewizji, istotnym warunkiem korzystania z wiadomości mediów publicznych jest ich rzetelność, obiektywizm, wiarygodność i dokładność ${ }^{11}$. Należy jednak mocno podkreślić, że odbiorcy mediów publicznych sygnalizują w swobodnych wypowiedziach intensywne wykorzystywanie ofert programowych innych niepublicznych nadawców, w tym mediów sieciowych, portali internetowych i mediów społecznych.

\section{Bibliografia}

Adoni H., Nossek H., Schrøder K.Ch., Cross-Media News Repertoires as Democratic Resources: A Cross-Cultural Research Project, 2013 (w przygotowaniu).

Audience Trends: Media Consumptions, MIS EBU, Geneva 2015.

Eurobarometer survey, European Commission, Bruxelles 2016.

Fletcher R., Nielsen R.K., Are News Audiences Increasingly Fragmented: A Cross-National Comparative Analysis of Cross-Platform News Audience Fragmentation and Duplication, „Journal of Communication” 2017, t. 67, nr 4.

Garlicki J., Różnorodność treści informacyjnych $w$ Polsce z perspektywy użytkownika, Raport $\mathrm{z}$ badań, Indicator, Warszawa 2015.

Horowitz M.A., Public Service Media and Challenge of Crossing Borders: Assessing New Models, „Medijskie Studije” 2015, t. 6, nr 12, s. 80-91.

Media Consumption Trends, MIS EBU, Geneva 2016.

11 Badania przeprowadzono w marcu i kwietniu 2015 roku, czyli przed wyborami parlamentarnymi, kiedy to wyłoniono nową większość sejmową, która uchwaliła nowelizacje Ustawy o radiofonii i telewizji z 29 grudnia 1992 r. prowadzące do wymiany dotychczasowych kierownictw Polskiego Radia i Telewizji Polskiej. 
Protokół Amsterdamski do Traktatu Europejskiego, Bruksela 1997.

McQuail D., Teoria masowego komunikowania, Wydawnictwo Naukowe PWN, Kraków 2007.

Reuters Institute, Digital News Report, Reuters Institute for the Study of Journalism, Oxford University, 2017.

Schrøder K.Ch., Methodological Pluralism as a Vehicle of Qualitative Generalization, „Participations: Journal of Audience and Reception Studies" 2012, t. 9, nr 2, s. 798-825.

Schrøder K.Ch., Audiences' News Media Repertoires as Resources for Public Connection: Preliminary Report from a Cross-National Comparative Study, paper presented at the ICA Conference, San Jose, Puerto Rico, 21-25 May 2015.

Schrøder K.Ch., Larsen B.S., The Shifting Cross-Media News Landscape: Challenges for News Producers, „Journalism Studies” 2010, t. 11, nr 4, s. 524-534.

Załącznik. Kategorie dla Q Kart

\section{Wiadomości telewizyjne/publicystyka (telewizor lub inne urządzenia)}

1. Wiadomości w telewizji publicznej - na żywo lub odtwarzane (Wiadomości, Panorama).

2. Wiadomości w kanale komercyjnym TV - na żywo lub odtwarzane (Fakty, Wydarzenia).

3. Wiadomości w telewizji regionalnej/lokalnej - na żywo lub odtwarzane.

4. Lekka publicystyka bieżąca - na żywo lub odtwarzane (talk-show Kuby Wojewódzkiego).

5. Poważna publicystyka bieżąca - na żywo lub odtwarzane (Fakty po Faktach, Minęła dwudziesta).

6. Krajowy 24-godzinny kanał informacyjny TV (TVP Info, TVN24).

7. Zagraniczny 24-godzinny kanał informacyjny TV (France 24, CNN, BBC World).

8. Gazeta telewizyjna.

\section{Radiowy serwis informacyjny lub publicystyka (odbiornik radiowy, inne urządzenie lub w internecie)}

1. Serwisy informacyjne w ogólnopolskim lub regionalnym radiu publicznym (PR1, PR3, rozgłośnie regionalne).

2. Serwisy informacyjne w stacji komercyjnej o charakterze ogólnym (Radio Zet, RMF FM).

3. Publicystyka w stacji radiowej o charakterze ogólnym i/lub w 24-godzinnej stacji informacyjnej (Śniadanie z radiem ZET, Poranki w TOK FM).

\section{Prasa drukowana}

1. Poważny dziennik ogólnopolski („Gazeta Wyborcza”, „Rzeczpospolita”).

2. Gazeta codzienna - tabloid („Fakt”, „Super Express”). 
3. Dziennik bezpłatny („Metro”).

4. Ogólnopolski magazyn informacyjny lub tygodnik opinii („Polityka”, „Newsweek”, „Wprost”).

5. Dziennik lokalny/regionalny.

6. Tygodnik/dwutygodnik/miesięcznik lokalny.

\section{Gazety i wiadomości nadawców multimedialnych}

1. Poważny ogólnopolski dziennik w internecie dostępny w komputerze, przez urządzenie mobilne itd. (Gazeta.pl, Rzeczpospolita.pl).

2. Ogólnopolski dziennik typu tabloid w internecie dostępny w komputerze, poprzez urządzenie mobilne itd. (Fakt.pl).

3. Bezpłatny dziennik $w$ internecie dostępny $w$ komputerze, przez urządzenie mobilne itd. (metroMSN).

4. Ogólnopolski magazyn informacyjny lub tygodnik opinii $\mathrm{w}$ internecie (Newsweek.pl, Polityka.pl).

5. Lokalny/regionalny dziennik w internecie dostępny w komputerze, przez urządzenia mobilne.

6. Lokalny tygodnik/dwutygodnik/miesięcznik w internecie dostępny w komputerze, urządzeniach mobilnych.

7. Serwis/portal informacyjny $\mathrm{w}$ internecie publicznego nadawcy radiowego i telewizyjnego (Polskieradio.pl, TVP.pl).

8. Serwis/portal informacyjny $\mathrm{w}$ internecie komercyjnego nadawcy radiowego/telewizyjnego (Radio Zet, TVN online).

9. Serwis/portal informacyjny $\mathrm{w}$ internecie zagranicznego nadawcy radiowego/telewizyjnego (BBC, „The New York Times”, „The Guardian”).

\section{Wiadomości w mediach społecznościowych}

1. Wiadomości na Facebooku dostępne w komputerze, na urządzeniach mobilnych.

2. Wiadomości na Twitterze dostępne w komputerze, na urządzeniach mobilnych.

3. Wiadomości w innych mediach społecznościowych dostępne w komputerze, na urządzeniach mobilnych, np. LinkedIn, Instagram, Pinterest itd.

4. Wiadomości rozpowszechniane przez media wideo w internecie, np. YouTube, Vimeo itp.

5. Blogi zawierające wiadomości dostępne w komputerze, na urządzeniach mobilnych itd.

\section{Wiadomości w innych mediach i poza mediami}

1. Wymiana wiadomości przez e-maile lub SMS-y. 
2. Czasopisma profesjonalne i branżowe (czasopisma związkowe, czasopisma stowarzyszeń zawodowych, fundacji).

3. Wiadomości wydawane przez agregatorów informacji lub spersonalizowane usługi informacyjne w portalach (Google News, Flipboard itp.).

4. Wiadomości z portali/serwisów internetowych (Onet, Wirtualna Polska, wPolityce.pl, naTemat.pl).

5. Ogólnopolskie, regionalne lub międzynarodowe serwisy informacyjne w internecie wydawane poza mediami (np. krajowe lub lokalne władze publiczne, partie polityczne, organizacje pozarządowe, instytucje wspólnoty europejskiej, UNESCO, Greenpeace itp.). 